\title{
Changing stress levels through gaining information on stress
}

\author{
SN Madu, Department of Psychology, University of the North \\ ES De Jong, Department of Psychology, University of the North
}

\section{Abstract}

Objective: The aim of this research was to find out the effect of the Information Phase of a Stress Management Program (SMP) on the perceptions of participants about their stress levels.

Method: A total sample of 100 workers (nursing staff, private business men and women. laboratory assistants, the protective services [foreman and security staff], as well as people in human resources departments) took part in this study. All the participants were from the Northern and Gauteng Provinces in South Africa. The Combined Hassles and Uplifts Scale (Folkman \& Lazarus, 1989) was used as an instrument to measure the perceived stress level of participants in a SMP.

Result: A significant reduction in stress levels was achieved among those who received the Information Phase of the SMP only, as well as those who received the whole stress management techniques. There was no significant difference between the amount of reduction in perceived stress-levels achieved among those that received the Information Phase of the SMP only, compared to that of those who received the whole techniques.

Conclusion: The authors conclude that where the resources are limited, only the information phase of a SMP may be given to desiring clients. That should help to save time and money spent on participating in SMPs. This should however not discourage the use of the whole SPM, where affordable.

Keywords: Stress Management Programs, Information Phase, Perception, Stress Level.

\section{Introduction}

Most current stress management programmes that exist have an introductory stage where information is given on what stress is and the influences of stress on the person (Briner, 1997: 61-67). However, research on the effectiveness of the Information Phase, usually presented in such programmes is lacking in South Africa generally.

The questions that immediately come to mind are: What is the effect of this first phase of an SMP on the participants in a SMP? Does it have an effect on the self-perceptions of participants regarding their stress levels? Answers to these questions could be used to shape SMPs in time and money spent on participating in such programmes - especially with regard to participants' perceived amount of control over their situations.

According to the Human Sciences Research Council (HSRC, 1997: 1-10), South Africa loses about R500 million per year due to the loss of productivity as a result of stress. It is not just only in the best interest of the South African economy to address this issue regarding stress, but it is also for the individuals who need the SMP. Much research (De Anda, 1998: 73-85: Holdevici, 1995: 161-171; Kantor, Schomer \& Louw, 1997: 16-21; Kline \& Snow, 1994: 105-121; McCain \& Smith, 1994: 221-227; McCourt-Mooney, 2000: 98-104; McNally \& Solomon, 1999: 20-26; Ross, Niebling \& Heckert, 1999: 312-316) has been done on the different techniques being implemented in stress management programmes (SMP). However, none of them have looked at the influence of the introductory phase of the SMPs to improve a concep- tual understanding of stress or stress management and its consequences.

Nicholson, Duncan, Hawkins, Belcastro \& Gold, (1988: 637641 ) evaluated 62 published reports on SMPs from numerous fields (see also Briner, 1997: 61-67). Their suggestion is that research needs to focus on levels and components of SMPs. Only one published research finding could be traced on the evaluation of an eclectic model as a basis for a stress management programme in South Africa (Kantor, Schomer \& Louw, 1997: 16-21). Short- and long-term changes in the lifestyles were researched and the course included the following aspects: healthy eating lifestyles, fitness, general health aspects and the application thereof, relationships, occupational stress and stress management resources. The researchers felt that the aspect of resources of stress management was not fully utilised. This aspect only included the spending of free time. Once again, the use of the information gaining-phase and its impact were not covered.

Uhlemann and Plater (1990: 3-16) suggest that information should be gathered in a situation with the aim of goal planning. According to McCain and Smith (1994: 221-227) a correlation exists between a person's evaluation of a situation and illnesses. Dimensions of the situation (undesirables, unpredictability, uncontrollability, extent and the aspect of duration or time), are helpful in giving a more objective view of the relationship between situations and their relationship with illnesses. These dimensions are perceived to be related to the person's beliefs, values, relationships and coping resources. 
The importance of giving patients suffering from chronic illnesses more information regarding their illnesses has been suggested by a number of researchers (Johnson, 1988; Olson. Huszti, Meason \& Seibert. 1989: 1-21; Weist, Finney, Barnard. Davis \& Olledick, 1993: 11-28) as this is likely to help the person suffering from an illness to gain more control over the illness.

In many parts of Africa, where, on the one hand, financial resources are often very limited, and on the other hand, many workers suffer from stress and other stress-related illnesses (Ebigbo, 1993: 396-401, 1996: 28-49: Bhana \& Haffejee. 1996: 431-434; Pretorius, 1993: 10-14, 1994: 771-777; Struempfer \& Bands. 1996: 67-75; van Wijk, 1997: 707-710), an inquiry into a time- and cost-effective method of reducing stress, is a necessity. The purpose of this study, therefore, is to investigate the effectiveness of the Information Phase of a SMP, and if found effective, to recommend it where time- and cost-effective methods of reducing stress is a necessity. No study of this kind has been conducted in South Africa. Therefore, this study will provide some baseline information on the matter in South Africa.

The hypotheses for this study are: 1. A significant reduction in stress levels will be achieved among those who received the Information Phase of the SMP only, as well as those who received the whole stress management techniques. 2 . There will be no significant difference between the amount of reduction in perceived stress-levels achieved among those that received the Information Phase of the SMP only, compared to that of those who received the whole techniques.

\section{Method}

The experimental method was used in this study, with pre-, between- and post- repeated measurements. This method was appropriate in this study since each participant formed part of both the experimental and the control groups (De Anda, 1998: 73-86; Rose \& Fiore. 1999: 235-252).

\section{Participants:}

Institutions and private business sector considered to be high in job-related stress levels were approached by one of the authors for possible participation of their workers in the study. Once an institution or business sector had accepted to participate, no other similar one was approached for the study. The reason for this exclusion was to ensure a wide representation of the target population is included in the study. A total of 100 participants took part in this study. They volunteered and registered for a stress management workshop for two weeks as part of their personnel development and skill training options. The first 20 participants who volunteered from each of the populations mentioned below were chosen for the study. The population were from the nursing staff of a psychiatric hospital in Pretoria, private business men and women in Pretoria and Johannesburg (chosen at random from telephone directories), laboratory assistants in Phalaborwa, the protective services (foreman and security staff at companies from Phalaborwa), and workers in the Human Resources Departments (personnel) in Pietersburg. Participation in the study was voluntary and was given free of charge; however, a prerequisite for participation was at least a Grade 12 educational level.

There were altogether 56 blacks and 44 whites; 46 males and 54 females. Among the blacks, there were 23 males and $33 \mathrm{fe}-$ males. Among the whites, there were 23 males and 21 females. Among all the participants, $16 \%$ were between 20 and 29 years old, $50 \%$ were between 30 and 39 years old, $24 \%$ were between 40 and 49 years old, and $10 \%$ were 50 years old or above.

\section{Instruments \\ The Questionnaire:}

The first part of the questionnaire contains the following demographic questions: gender, skin colour and age. The second part contains the Combined Hassles and Uplifts Scale developed by Folkman \& Lazarus (1989). The questionnaire is a selfadministered questionnaire, consisting of 53 items that are scored ranging from 0 (not applicable) to 3 (a great deal). The potential sources of hassles or uplifts covered by the questionnaire can be grouped into the following subheadings: future security, time, work, household responsibilities, health. inner concerns, financial responsibilities and environment. Questions are in English and stated in such a way that they are open to projection and thus also to subjectivity. In their approach, questions were phrased in such a way that they measure the individual's appraisal of potential threat, harm, loss or challenge. The Combined Hassles and Uplifts Scale can be used to investigate stress either as an independent or a dependent variable

Instructions on how to answer the questionnaire were that the questions had to be answered on both the Hassles and Uplifts scores and within a period of one week (for the past week). Scoring the CHUS on uplifts has two advantages: (I) It may point to aspects that serve as a buffer for negative experiences or consequences to stressors, and (ii) it de-emphasises the negative effect of answering and focussing only on negative stressors as a consequence of the testing procedures. Chronbach Alpha and Split-half reliability for the whole scale used were .81 and .72 respectively for this sample. The global validity of the scale has been established since it correlates significantly $(r=0.82, p<0.0001)$ with the global experience of stress (Dumont, Tarabulsy, Gagnon, Tessier \& Provost, 1998: 57-71).

\section{The Stress Management Programme:}

Since many authors pointed to the preference of using an eclectic model in compiling SMPs (Brems, Amodei \& Scott, 1989: 175-179; Courtney \& Escobedo, 1990: 306-310: Kushnir \& Malkinson. 1993: 195-206; McCain \& Smith, 1994: 221-227; Nicholson et al., 1988: 637-641), one of the authors used this approach in compiling the whole SMP. The A-B-C-Theory of Albert Ellis (Corey, 1996) was used as an introduction to clarify the importance of perspectives and beliefs in experiences. The advantage of forming belief systems or a frame of reference was explained in that a situation does not always have to be evaluated as being something totally unique. Disadvantages, however, could be that a person does not always see the differences between situations and could therefore have a narrowed 
perception of the situation and make less realistic evaluations in the given situation.

The basis of the theoretical perspective in the SMP was the Transactual Theory of Lazarus and Folkman (1984). While using this theory the A-B-C-Theory (Corey, 1996) was integrated with regard to perceived interpretation of a situation into the Transactual Theory (Lazarus \& Folkman; 1984).

Specific attention is given to the way assumptions are formed and the advantages and disadvantages of assumptions and belief systems. By focussing on the realistic evaluation of stressors, the amount of control a person perceives to hold is being introduced. The terms, internal and external locus of control, were then explained and used to introduce the medical model of Fisher (1996: 16-22) and the "Fight-or-Flight-Reaction" (Everley, 1989) to explain related illnesses. Since the work of Fisher (1996: 16-22) seems somewhat complicated and too rich in neurological terminology, this theory was merely mentioned with referrence to the aspect of control and the different physiological consequences this holds.

The stress management programme consists of two distinct phases: The information phase, Phase 1 , is normally presented as the introductory phase during the first three sessions within the first week; and coping strategies, Phase 2, is presented during the last three sessions within the second week to the participants. This is the stage where the Stress Management Techniques are presented. A session lasts for about one hour thirty minutes. The employers of the participants or the participants themselves could afford a maximum of two weeks for the whole exercise.

\section{Contents of the Programme}

The information phase focuses on information on the physical and psychological symptoms of stress, the influence thereof on the person, as well as the theoretical perspective of the programme on which it is based. It is also used to find out the methods they currentiy use to attend to the stressful situations they experience. Lastly, information is given on alternative coping styles.

During the second phase, role-playing is used to bring about new perspectives. By making use of this technique, group members get the chance of practising new techniques in a controlled environment (Corey, Corey, Callanan \& Russell, 1992). The new techniques can be categorised into the following two broad areas: (1) Emotional: It includes the following technique: relaxation, shifting of focus, denial, expression of emotions, and humour; (2) Problem-orientated: It includes: problem-solving, communication, and social ability techniques.

\section{Procedure}

The personnel managers of the different participating institutions asked for volunteers among their employees who would participate in a stress management workshop. The first 20 volunteers formed the group for the stress management workshop in their institution. For those from the pri- vate sector, a neutral place was arranged for them in Johannesburg. The workshop was organised and conducted by one of the authors.

It was important to establish group cohesion as soon as possible during the different application procedures in the SMP. This had to be achieved without sacrificing the ethical guidelines printed by the Association for Specialists in Group Work Executive Board on June 1, 1989, and reprinted by Corey, et al. (1992) with approval from the American Association for Counselling and Development. Disclosure, confidentiality and goal of the research project were of utmost importance in the development of the SMP (Corey, et al., 1992) and, as such, each participant received his or her own SMP manual. Group members were orientated with regard to the aims and purposes of the programme in the first session. Group rules were also made clear at this point

Since the main aim of this study was to see if the self-perceptions of the participants would change with regard to personal stress, by giving them information on stress, the study used a subjective approach with regard to stress and stressors. For this reason each participant was regarded as forming part of both the control group and the experimental group and no population norms were needed to establish standardisation of the South African population.

During the SMP, Phase 1 was presented (within one week) as the Introductory Phase (Information Phase) during the first three sessions to all the participants, followed by Phase 2 (the actual stress management technique phase) which was presented to only half of the participants within the second week. Participants were tested on the Hassles and Uplifts Scale before any subjection to the SMP commenced (Test 1). This testing is to be used as the baseline data.

Randomised selection was used to decide on the participants for the two distinct application procedures (receiving only the first phase of the programme or receiving the whole SMP). The second testing (Test2) was done after completion of the first phase (first week) of the SMP. After Test 2, the Information group was allowed to go, while the other group remained for another one week. A third testing (Test 3 ) was done after another week (in which half of the participants received Phase 2 of the SMP). The fourth testing (Test 4) was done six months after the last testing was done, to see whether the affected changes persisted among all the participants. A convenient date and time was fixed when the Information group came back for Tests 3 and 4; and the same applied to the group for Test 4. The same Hassles and Uplifts Scale was used in each case. In each case, the Hassles and Uplifts Scale took about 5 to 10 minutes to complete. Each of the programmes and tests took place in a seminar-room setting. All tests were hand delivered and were collected thereafter. The researchers did the coding and the cross-checking.

\section{Data Analysis}

The data was analysed using the Statistical Package for Social Sciences (SPSS). The self-perceived stress level for each test was calculated by subtracting the total scores on the Uplifts 
Scale from the total scores on the Hassles Scale, since the increase on the score on any item in the Uplifts Scale reduces the level of perceived stress indicated on the Hassle Scale on the same item. The descriptive statistics and the Analysis of Variance (ANOVA) was the statistical method used.

\section{Result}

Table 1 presents the mean scores for stress levels of all the participants during Tests $1,2,3$, and 4 . levels will be achieved among those who received the Information Phase of the SMP only, as well as those who received the whole stress management techniques. Analysis of Variance (ANOVA) for Repeated Measures (General Linear Model) shows that the decrease in stress levels from Test 1 to Test 4 in each group is significant (Pillai's Trace: $F=319.642, d f=3, p<0.05$ ). Thus, the hypothesis is supported.

The second hypothesis states that there will be no significant difference between the amount of reduction in perceived stress-

\section{Table 1: Mean scores for stress levels during Tests 1, 2, 3 \& 4 among all the participants}

\begin{tabular}{|l|l|l|l|l|}
\hline Tests & Phase & Mean & Std. Deviation & N \\
\hline 1 & Information & -13.16 & 39.75 & 50 \\
\cline { 2 - 5 } & Information \& Techniques & -21.92 & 31.43 & 50 \\
\cline { 2 - 5 } & Total & -17.54 & 35.92 & 100 \\
\hline 2 & Information & -34.32 & 37.42 & 50 \\
\cline { 2 - 5 } & Information \& Techniques & -35.00 & 31.41 & 50 \\
\cline { 2 - 5 } & Total & -34.66 & 34.37 & 100 \\
\hline 3 & Information & -42.28 & 35.95 & 50 \\
\cline { 2 - 5 } & Information \& Techniques & -47.96 & 28.93 & 50 \\
\cline { 2 - 5 } & Total & -45.12 & 32.59 & 100 \\
\hline \multirow{2}{*}{4} & Information & -50.22 & 33.90 & 50 \\
\cline { 2 - 5 } & Information \& Techniques & -58.26 & 26.40 & 50 \\
\cline { 2 - 5 } & Total & -54.24 & 30.50 & 100 \\
\hline
\end{tabular}

Table 1 shows that perceived stress continuously reduced when moving from Test 1 to Test 4 for the two groups.

The first hypothesis states that a significant reduction in stress levels achieved among those that received the Information Phase of the SMP only, compared to that of those who received the whole techniques. One Way ANOVA shows that at each Test, the stress level of one group does not differ signifi- 
cantly from that of the other group (for Test $1: F=1.494, \mathrm{df}=1$, $\mathrm{p}>0.05$; for Test $2: \mathrm{F}=0.010, \mathrm{df}=1, \mathrm{p}>0.05$; for Test $3: \mathrm{F}=0.758$, $\mathrm{df}=1, \mathrm{p}>0.05$; for Test $4: \mathrm{F}=1.75 \mathrm{l}, \mathrm{df}=1, \mathrm{p}>0.05$ ). Thus, the second hypothesis is also supported.

\section{Discussion}

A significant reduction in stress levels was achieved among those who received the Information Phase of the SMP only, as well as those who received the whole stress management techniques. Thus, the Information Phase of the SMP alone may equally have the desired effect on the participants. This can be explained by using the A-B-C-Theory of Ellis (Corey, 1996: 1050 ). Possible alternatives to stress were presented to the participants by increasing the participants' information regarding stress. This might cause the participant to dispute underlying belief systems. The discrepancy that started to develop might have, therefore, then formed the driving force to lower stress levels. According to the Transactual Theory of Lazarus \& Folkman (1984: 1-105), the Primary Appraisal Phase of a stressful situation forms the first step in coping procedures. Increasing information regarding stress might increase the perceived severity or frequency of stress and stressors. This could in turn lead to finding solutions to such stressors in order to decrease stress levels during the Secondary Appraisal Phase of this theory. What is thus a possible explanation to the above result is an underlying increase of the awareness of stress (whether in frequency or severity) which forms the driving force in this case to find solutions to these stressors.

Uhlemann \& Platter (1990: 3-16) explains the possibility that people might have difficulty in accepting negative thoughts or evaluations, and may therefore put greater effort into changing the situation. An underlying increase in 'Hassles' may therefore be present in such a way that they not only motivate the participant to change the severity or frequency of the stress or stressor, but may also cause a shift in the perception of a disstressor ('Hassle') to an eustressor ('Uplift').

There was no significant difference between the amount of reduction in perceived stress-levels achieved among those that received the Information Phase of the SMP only, compared to that of those who received the whole techniques. The differences between the base-line scores (Test 1) and the long-term outcomes (Test 4) of those who were only exposed to the Information Phase of the SMP, compared to that of those who received the full SMP were seen as follows: All the groups showed lowered scores (stress level) even on a long-term outcome basis regarding their self-perceptions on stress. This implies that although the whole stress management techniques have a positive impact on perceptions of stress, the Information Phase of an SMP only plays also a significant and important role in the reduction of perceived stress level over a prolonged period. Thus, where financial resources are limited, the information phase alone can be given to desiring clients. According to our findings, the information phase alone can give the desired significant reduction in perceived stress levels. In many parts of Africa, where, on the one hand, financial resources are often very limited, and on the other hand, many workers suffer from stress and other stress-related illnesses (Ebigbo, 1993: 396-401, 1996: 28-49; Bhana \& Haffejee, 1996: 431-434; Pretorius, 1993: 10-14, 1994: 771-777; Struempfer \& Bands, 1996: 67-75; van Wijk, 1997: 707-710), this time- and cost-effective method of reducing stress is a necessity. This result could also point to the development of own stress management techniques by participants who were only exposed to the Information Phase, enhancing self-perceptions and stimulating a greater tendency to an internal locus of control.

\section{Limitations of the Study}

Some (e.g., physiological) tests could have been used in addition to the CHUS to throw more light on the physiological aspects of stress (see also the theory of Fisher, 1996: 16-22). This might also have helped in giving a more comprehensive explanation of the underlying changes in stress levels. The absence of a separate control group in this study does not allow one to find out the effect of other possible factors, like the passage of time and demand characteristics, on the stress levels.

\section{Conclusions}

The Information Phase of an SMP plays a significant role in changing self-perceptions regarding stress in a SMP and puts a question mark the necessity for the whole stress management techniques. The authors recommend that research on SMPs should focus more on the processes that take place in an SMP in order to give participants more value for their time and money spent by participating in such programmes. Future presentations of an SMP could in fact focus more on the Information Phase of an SMP for an initial, and long-term decline in perceptions of stress. It could thus be an option to present only an Information Phase as an SMP, where saving time and money is a necessity. However, where time and money are available, participation in the whole SMP should be encouraged.

\section{References}

BHANA, A \& HAFFEJEE, N 1996: Relation among measures of burnout, job satisfaction, and role dynamics for a sample of South African child-care social workers. Psychological Reports. $79(2): 431-434$.

BREMS, C; AMODEI, N \& SCOTT, A 1989: Stress management program for psychiatric inpatients. Psvchiatric-Hospital. 10(4): 175-179.

BRINER, R 1997: Improving stress assessment: Towards an evidence-based approach to organisational stress interventions. Journal of Psvchosomatic Research. 43(1): 61-67.

BURNS, R 1987: Coping with Stress. Pacific Grove: Brooks/ Cole Publishing Company.

CARSON, RC; BUTCHER, JN \& COLEMAN, JC 1988: Abnormal Psychology and Modern Life. New York: Harper Collins Publishers.

COREY, G 1996: Theory and Practice of Psychotherapy. Pacific Grove: Brooks/Cole Publishing Company.

COREY, G; COREY, MS; CALLANAN, P \& RUSSELL, JM 1992: Group Techniques. California: Brooks/Cole Publishing Company. 
COURTNEY, C \& ESCOBEDO, B 1990: A stress management programme: Inpatient-to-outpatient continuity. AmericanJournal-of-Occupational-Therapy. 44(4): 306-310.

\section{DUMONT,M; TARABULSY,GM; GAGNON,J; TESSIER, R}

\& PROVOST, M 1998: Validation francaise d'un inventaire de micro-stresseurs de la vie quotidienne: combinaison du "Daily Hassles Scale" et du "Uplifts Scale". Journal International de Psvchologie. 33(1): 57-71.

EBIGBO, PO 1993: Somatisierungserscheinungen bei Nigerianern - diagnostische Versuche und therapeutische Ansetze. Psychotherapie. Psychosomatik. Medizinische Psychologie. 43 (11): 396-401.

EBIGBO, PO 1996: Somatic complaints of Nigerians. Journal of Psvchology in Africa. 1 (6): 28-49.

EVERLEY, GS 1989: A Clinical Guide to the Treatment of the Human Stress Response. New York: Plenum Press.

FISHER, S 1996: Life change, personal control and disease. Suid-Afrikaanse Tydskrif vir Sielkunde. 261 1 ): 16-22.

FOLKMAN, S \& LAZARUS, RS 1989: Manual: Hassles and Uplifts Scales. Sampler Set. California: Mind Garden. Inc.

HENDERSON, PA; KELBEY, TA \& ENGEBRETSON, KM 1992: Effects of a stress-control programme on children's locus of control, self-concept, and coping behavior. SchoolCounselor, 40(2):125-130.

HOLDEVICI, I 1995: Cognitive-experiential psychothera-peutical model in hypnotic state in patients with neurotic stress related troubles. Revue-Roumaine-de-Psychologie. 38(2): 161-171.

HUMAN SCIENCES RESEARCH COUNCIL (South Africa) 1997: Bestuurstres - of die kuns van ewewig in die lewe. Pretoria: RGN-uitgewers.

JOHNSON, DW 1988: Reaching Out: Interpersonal Effectiveness and Self-Actualization. Fifth Edition. New York: Allyn and Bacon.

KANTOR, L; SCHOMER, H \& LOUW, J 1997: Lifestyle changes following a stress management programme: an evaluation. Suid-Afrikaanse Tydskrif vir Sielkunje. 27(1): 16-21.

KLINE, ML \& SNOW, DL 1994: Effects of a worksite coping skills intervention on the stress, social support, and health outcomes of working mothers. Journal-of-Primary-Prevention. 15(2): 105-121.
KUSHNIR, T \& MALKINSON, R 1993: A Rational-Emotive Group Intervention for Preventing and Coping with Stress among Safety Officers. Journal of Rational-Emotive \& Cognitive-Behavior Therapy. 11(4): 195-206.

LAZARUS, RS \& FOLKMAN, S 1984: Stress, appraisal and coping. New York: Springer.

MCCAIN, NL \& SMITH, JC 1994: Stress and Coping in the Context of Psychoneuroimmunology: A Holistic Framework for Nursing Practice and Research. Archives of Psvchiatric Nursing. 8(4): 221-227.

MCCOURT-MOONEY, M 2000: Spotlight. Journal of Managerial Psvchology. 15(1/2): 98-104.

MCNALLY, VJ \& SOLOMON, RM 1999: The FBI's critical incident stress management program. FBI Law Enforcement Bulletin. 68(2): 20-26.

NICHOLSON, T; DUNCAN, DF; HAWKINS, W; BELCASTRO, PA \& GOLD, R 1988: Stress Treatment: Two Aspirins, Fluids, and one More Workshop. Professional Psychology: Research and Design. 19(6): 637-641.

OLSON, RA; HUSZTI, HC; MEASON, PJ \& SEIBERT, JM 1989: Journal of Pediatric Psychology. 14(1): 1-21.

PRETORIUS, TB 1993: Commitment, participation in decisionmaking and social support: Direct and moderating effects on the stress-burnout relationship within an educational setting. South African Journal of Psychnlogy. 23 (1): 10-14.

PRETORIUS, TB 1994: Using the Maslach Burnout Inventory to assess educator's burnout at a university in South Africa. Psychological Reports. 75 (2): 771-777.

ROSE, DS \& FIORE, KE 1999: Practical considerations and alternative research methods for evaluating Human Resource programs. Journal of Business \& Psvchology. 14(2): 235-251.

ROSS, SE; NIEBLING, BC \& HECKERT, TM 1999: Sources of stress among college students. College Student Journal. 33(2): 312-317.

STRUEMPFER, DJW \& BANDS, J 1996: Stress among clergy: An exploratory study on South African Anglican priests. South African Journal of Psvchology. 26 (2), 67-75.

UHLEMANN, MR \& PLATER, SA 1990: Effects of self-statements and coping strategies on adaptational outcomes of stress. Canadian-Journal-of-Counseling. 24(1): 3-16.

VAN WIJK, C 1997: Factors influencing burnout and job stress among military nurses. Military Medicine. 162 (10): 707 710. 
WEIST, MD; FINNEY, JW; BARNARD, MU; DAVIS, CD \&

OLLEDICK, TH 1993: Empirical Selection of Psychosocial Treatment Targets for Children and Adolescents with Diabetes. Journal of Pediatric Psychology, 18(1): 11-28. 